\title{
Analysis of the mutational landscape of classic Hodgkin lymphoma identifies disease heterogeneity and potential therapeutic targets
}

\author{
Elena Mata ${ }^{1, *}$, Antonio Díaz-López ${ }^{1, *}$, Ana M. Martín-Moreno, Margarita Sánchez- \\ Beato $^{2}$, Ignacio Varela ${ }^{3}$, María J. Mestre ${ }^{4}$, Carlos Santonja5, Fernando Burgos ${ }^{6}$, \\ Javier Menárguez ${ }^{7}$, Mónica Estévez ${ }^{8}$, Mariano Provencio², Beatriz Sánchez- \\ Espiridión' ${ }^{9}$, Eva Díaz ${ }^{1}$, Carlos Montalbán ${ }^{8}$, Miguel A. Piris ${ }^{5}$ and Juan F. García ${ }^{1}$

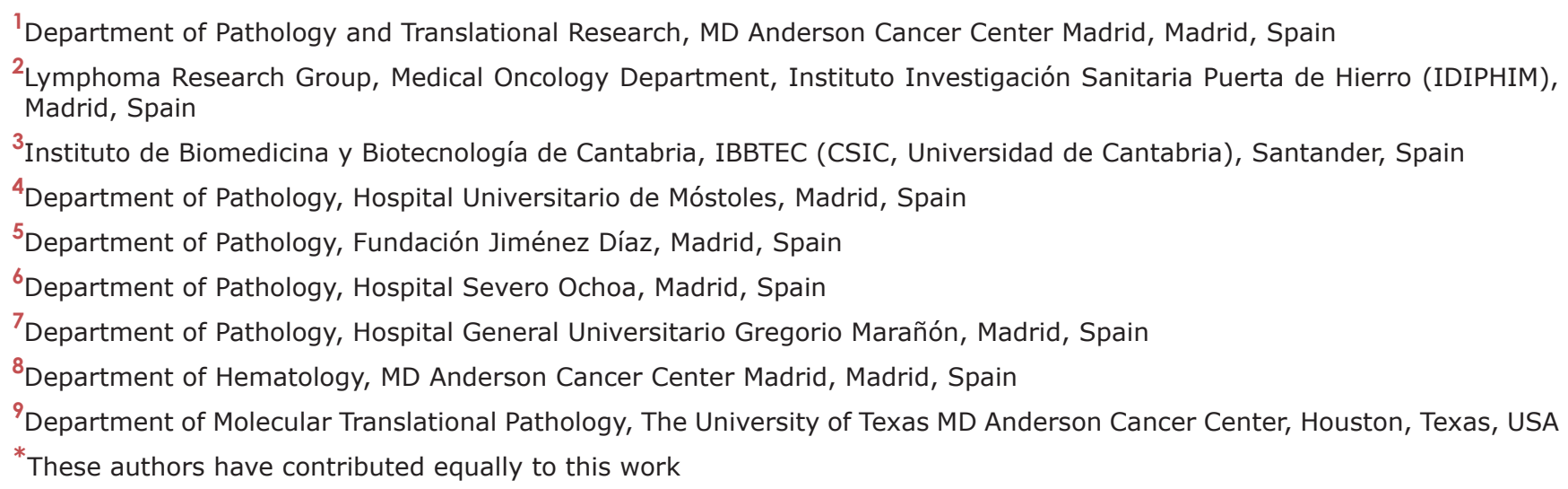 \\ Correspondence to: Juan F. García, email: jfgarcia@mdanderson.es \\ Keywords: mutational analysis; Hodgkin lymphoma; B-cell receptor; BTK; therapeutic target \\ Received: August 31,2017 Accepted: November 13, $2017 \quad$ Published: November 30, 2017 \\ Copyright: Mata et al. This is an open-access article distributed under the terms of the Creative Commons Attribution License 3.0 \\ (CC BY 3.0), which permits unrestricted use, distribution, and reproduction in any medium, provided the original author and source \\ are credited.
}

\section{ABSTRACT}

Defining the mutational landscape of classic Hodgkin lymphoma is still a major research goal. New targeted next-generation sequencing (NGS) techniques may identify pathogenic mechanisms and new therapeutic opportunities related to this disease. We describe the mutational profile of a series of $57 \mathrm{cHL}$ cases, enriched in Hodgkin and Reed-Sternberg (HRS) cells.

Overall, the results confirm the presence of strong genomic heterogeneity. However, several variants were consistently detected in genes related to relevant signaling pathways, such as GM-CSF/IL-3, CBP/EP300, JAK/STAT, NF-kappaB, and numerous variants of genes affecting the B-cell receptor (BCR) pathway, such as $B T K$, CARD11, BCL10, among others. This unexpectedly high prevalence of mutations affecting the BCR pathway suggests some requirement for active BCR signaling for CHL cell viability. Additionally, incubation of a panel of $\mathrm{cHL}$ cellular models with selective BTK inhibitors in vitro constrains cell proliferation and causes cell death. Our results indicate new pathogenic mechanisms and therapeutic opportunities in this disease.

\section{INTRODUCTION}

Classic Hodgkin lymphoma (cHL) consists of a clonal proliferation of the distinctive Hodgkin and Reed Sternberg (HRS) cells, diluted in a reactive inflammatory microenvironment [1]. HRS cells have customarily been characterized by a defective $\mathrm{B}$ cell expression program [2], probably as a result of the downregulated expression of numerous B cell transcription factors [3], and epigenetic mechanisms [4]. Thus, although HRS cells are derived from mature B cells, they have largely lost the $\mathrm{B}$ cell phenotype and are unable to express immunoglobulins / B-cell receptor (BCR) and other B cell surface markers. 
Few studies have attempted to identify gene mutations in $\mathrm{cHL}$, and only mutations in specific members of the NF-kappaB and JAK/STAT pathways have been consistently identified [5-8]. A major limitation of gene sequencing of cHL is the scarcity of tumoral HRS cells, which account for fewer than $1-2 \%$ of all cells, as identified by standard CD30 immunostaining.

The advances in next-generation sequencing (NGS) technologies have allowed rapid genome-wide characterization of single-nucleotide variants (SNVs) and indels in cancer, and the genetic landscapes of many solid tumors and hematological malignancies have been demonstrated [9-12]. The first whole exome sequencing analyses of primary HRS cells have recently been described, in which beta-2-microglobulin (B2M) was identified as the most commonly altered gene [12]. However, this study focused on the detection of highly prevalent mutations, and had obvious limitations for the detection of subclonal variants due to the shallow depth of sequencing inherent in full exome analysis technologies.

In recent years, the sensitivity and specificity of NGS techniques have been greatly improved by simultaneously testing selected genes, arranged in specific comprehensive gene panels. This approach is also useful when sample material is limited, and even for formalinfixed paraffin-embedded (FFPE) tissue samples. We hypothesized that combining sequencing techniques with increased coverage, and more sensitive and specific bioinformatic algorithms, could also allow identification of pathogenic SNVs that are present at low frequencies in this disease.

Here we analyze the genomic heterogeneity of a large series of $57 \mathrm{cHL}$ cases. We used a semiconductorbased (Ion Torrent) sequencing platform with a customdesigned gene panel coupled with HRS cell-enrichment procedures to establish the mutational landscape of this tumor in greater detail. Several variants were consistently identified in genes related to relevant signaling pathways, such as GM-CSF/IL-3, JAK/STAT, NF-kappaB, and also many variants of genes affecting the BCR pathway, such as BTK, CARD11, BCL10, and others. Moreover, selective-BTK inhibitors were found to constrain cell proliferation and cause cell death in cHL cellular models with comparable efficiencies to other cell B-cell lymphoma models.

\section{RESULTS}

\section{Recurrent mutations in $\mathrm{cHL}$}

Clinical characteristics of the patients are described in Table 1. It is of particular note that $34 \%$ of cases in this series had primary refractory $\mathrm{cHL}$, and $28.3 \%$ of tumors were EBV-positive.

Using the described NGS targeted protocol, the number of candidate somatic SNVs detected per case was found to range from 27 to 587. Cases with low numbers of SNVs detected in each duplicate had high concordance ratios (Supplementary Figure 1), whereas cases with high numbers of SNVs showed low concordance, which means that there is either very extensive clonal diversity (many mutations with very low variant allele frequencies) or that some SNVs actually represent sequencing errors in cases with poorer DNA preservation. This observation confirms the presence of strong genomic heterogeneity, and reinforces the relevance of filtering SNVs using duplicate analyses in this study.

Figure 1 and Supplementary Table 4 summarize the details of the SNVs. After filtering, we found 63 concordant SNVs in 57 samples. The mean read depth of the targeted regions was 740.32. Non-synonymous SNVs were identified in 23 out of the 57 cases $(40.35 \%)$. We found a high percentage of $\mathrm{C}>\mathrm{T}$ changes (nearly $46 \%$ ), probably due to the dipyrimidine context (Supplementary Table 4) [13]. As other authors have noted [8], some of the cases had more than one SNV per gene, as in the cases of EP300, BTK, CSF1R and CD19.

We found the predicted damaging effect of the SNVs in 24 out of the 36 genes analyzed $(66.6 \%)$. Of these, 4 genes had mutation rates greater than $10 \%$ : $C S F 2 R B$, EP300, STAT6, and BTK (Figure 1 and Supplementary Figure 2). This finding may reflect the importance of the deregulation of relevant signaling pathways (such as JAK/STAT and BTK), and the relevance of epigenetic deregulation.

Some of the variants were also identified in cHLderived cell lines, and validated using Sanger sequencing. They affected genes such as CARD11, STAT6, CSF2RB, $B 2 M$, and NFKBIA (Figure 2 and Supplementary Table 5). Consistent with our results, some of these SNVs, such as those of STAT6, B2M, and NFKBIA, have been described as mutations in previous NGS analyses of cHL cell lines [14].

\section{Functional studies}

Unexpectedly, we identified a large number of mutations affecting the $B T K$ gene $(10.3 \%$ of cases) and other members of the BCR pathway (such as CARD11, $B C L 10$, and NFKBIA, which were present in up to $21 \%$ of cases), suggesting that there are some dependencies of active BCR signaling despite the known absence of BCR expression in HRS cells. To evaluate BCR signaling activation in cHL, $6 \mathrm{cHL}$ cell lines, the HBL1 ABC-type DLBCL cell line, the DOHH2 GC-type DLBCL cell line, and the control HEK293T and HeLa cell lines were interrogated. The NFkappaB subunit p52 was strongly expressed in all the cHLs analyzed and both DLBCL cell lines, providing further evidence of the well-known role of NFkappaB in lymphocyte survival (Figure 3A). Since NFkappaB activation may be the result of activation of several survival pathways, we analyzed the expression of 
Table 1: Clinical characteristics of patients

\begin{tabular}{|c|c|c|}
\hline FEATURE & $\mathbf{N}$ & $\%$ \\
\hline \multicolumn{3}{|l|}{ Age (years) } \\
\hline$<45$ & 37 & 68.52 \\
\hline$\geq 45$ & 17 & 31.48 \\
\hline \multicolumn{3}{|l|}{ Gender } \\
\hline Male & 26 & 48.15 \\
\hline Female & 28 & 51.85 \\
\hline \multicolumn{3}{|l|}{ IPS } \\
\hline $0-2$ & 35 & 64.81 \\
\hline$\geq 3$ & 19 & 35.19 \\
\hline \multicolumn{3}{|l|}{ Outcome } \\
\hline Refractory & 18 & 33.96 \\
\hline Complete response & 35 & 66.04 \\
\hline \multicolumn{3}{|l|}{ Ann Arbor Stage } \\
\hline$<\mathrm{IV}$ & 36 & 67.92 \\
\hline$\geq \mathrm{IV}$ & 17 & 32.08 \\
\hline \multicolumn{3}{|l|}{ Histology } \\
\hline Nodular sclerosis & 34 & 59.64 \\
\hline Mixed cellularity & 13 & 22.8 \\
\hline Lymphocyte-rich & 6 & 10.53 \\
\hline NA & 4 & 7.03 \\
\hline \multicolumn{3}{|l|}{ EBV } \\
\hline Positive & 15 & 28.3 \\
\hline Negative & 38 & 71.7 \\
\hline
\end{tabular}

other proteins involved in BCR signaling. BTK protein expression was found in all cHL cell lines at similar levels, unlike BTK Tyr223 phosphorylation, which was only found in DLBCL cells (HBL1 and DOHH2) and some of the cHL cell lines (L428 and HDML2) (Figure 3A). In addition to BTK expression, activation of NFkappaB via BCR signaling was explored by CYLD cleavage, a direct downstream target protein of the BCR pathway. CYLD cleavage by western blot was observed in all cHL cell lines and DLBCL cell lines at similar levels, supporting the hypothesis that there is some level of basal activation of the BCR cascade in cHL.

We therefore examined the activity of selective BTK inhibitors in cHL cell lines. First, we used ibrutinib, a specific BTK inhibitor approved for therapy for various $B$ cell-derived malignancies. Ibrutinib toxicity curves showed a similar $\mathrm{IC}_{50}$ range of $10-50 \mu \mathrm{M}$ in both models: DLBCL (HBL1) and cHL cell lines, without significant differences (Figure 3B). To confirm these findings we incubated the cells with a second experimental BTK inhibitor (AVL-292), which yielded similar $\mathrm{IC}_{50}$ ranges in all the cell lines analyzed. Indeed, the $\mathrm{IC}_{50}$ after BTK inhibition with ibrutinib was similar in other cell models of B-cell malignancy, such as mantle cell lymphoma (data not shown).

Consistent with this, IHC staining of the tumor samples using TMAs showed common BTK protein expression in the neoplastic HRS cells ( $72 \%$ of cases), with unusually strong expression in $8 \%$ of cases (Figure 4). We also found a significant correlation between FFS and the presence of BTK gene mutations (Figure $4 C$ ) and a just-insignificant correlation with BTK protein expression (Figure 4D).

\section{DISCUSSION}

Although cHL is generally a highly curable disease, a significant fraction of patients nevertheless have relapsing disease and eventually die due to treatment resistance or late treatment-associated toxicities [15]. 
Thus, the identification of new therapeutic alternatives and the better biological characterization of the subgroup of patients with refractory disease remain major research goals. Here we describe the mutational profile of $\mathrm{cHL}$ using data initially generated in the initial discovery cohort and extend these observations to a large series of $57 \mathrm{cHLs}$ using targeted deep sequencing with a restricted list of 36 genes and duplicate experiments.

We detected recurrent mutations in 24 genes. Other authors have reported some of the genes commonly mutated in cHL, such as NFKBIA [16] and FAS [17]. It is of note that many of the variants identified here have also been detected in the recent NGS analysis of primary HRS cells [12], including $A B L 1, B 2 M, C A R D 11, C S F 2 R B$,
MYB, NFKB2, NFKBIA, and STAT6, among others. Differences in isolation techniques, sequencing methods, filtering criteria, and limitations due to small sample sizes may be responsible for some of the discrepancies in frequencies. We also identified some previously unreported SNVs in BTK and EP300.

We identified several SNVs in genes that had previously been described in NGS studies of DLBCL. We consistently found variants affecting CARD11, STAT6, $C R E B B P$, and $C M Y B$, as described in ABC-type DLBCL $[9,11]$, and $S T A T 6$, as known in primary mediastinal large B-cell lymphoma [10]. These findings are consistent with the well-known molecular similarities between $\mathrm{cHL}$ and these lymphoma types $[10,18]$.

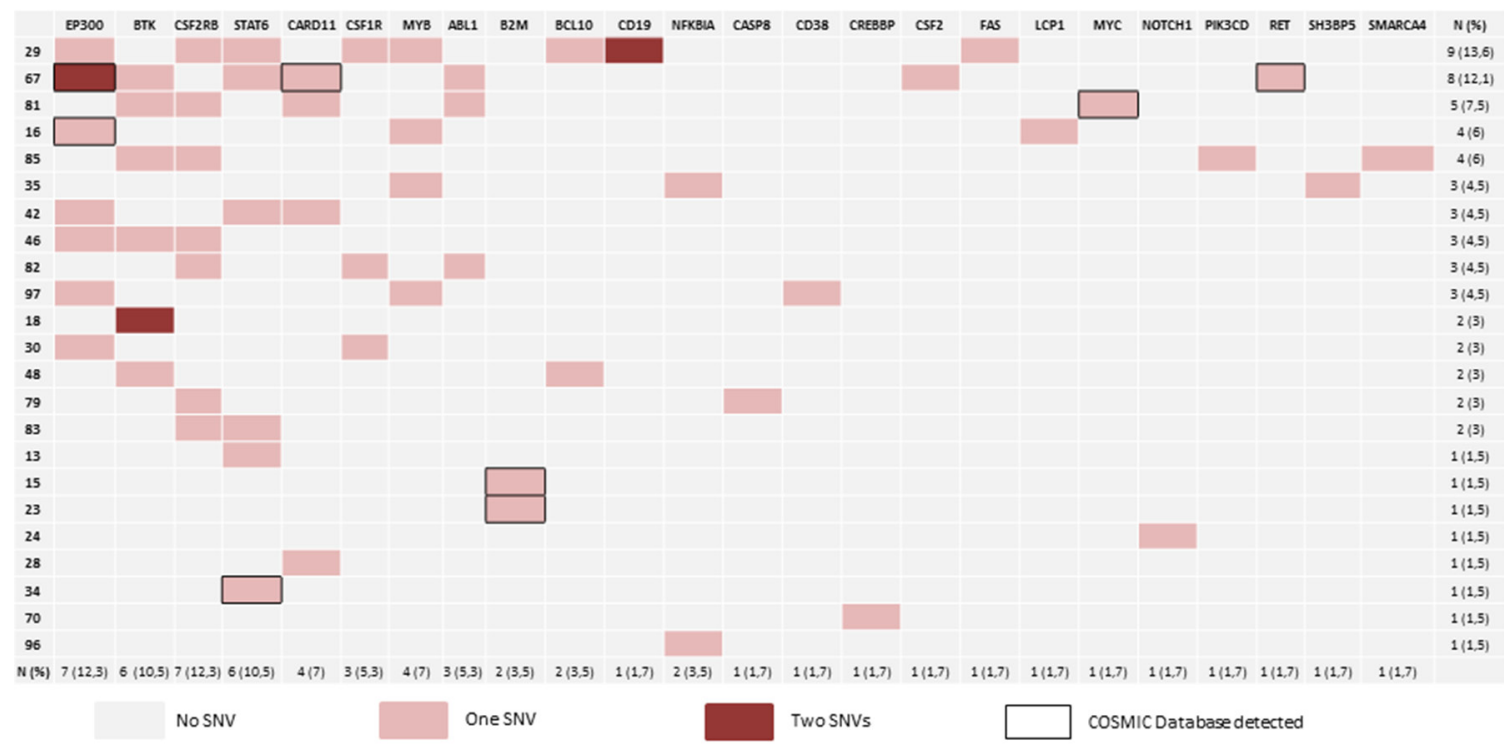

Figure 1: Mutational landscape. The diagram shows the distribution of gene variants. $40.3 \%$ of samples have at least $1 \mathrm{SNV}$ after filtering. We identified variants in $66.6 \%$ of the selected genes. One SNV is indicated in red, while genes with more than two SNVs are indicated in dark red. The final two columns indicate the number and percentage of mutated genes per case. The bottom two rows indicate the number and percentage of cases with at least one SNV.

A

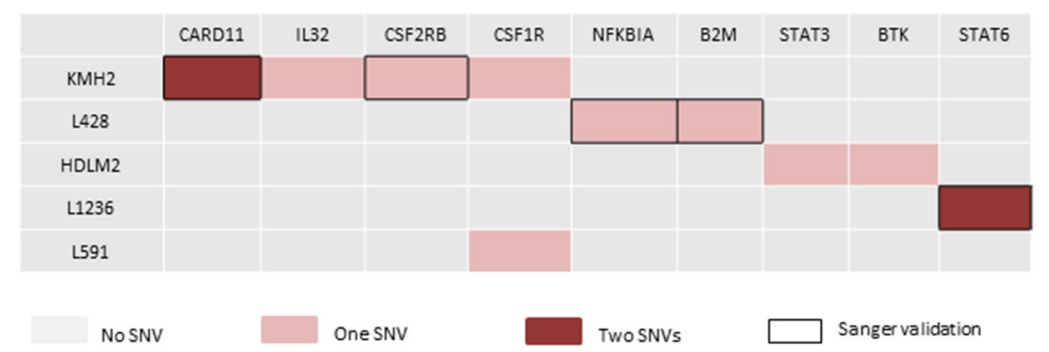

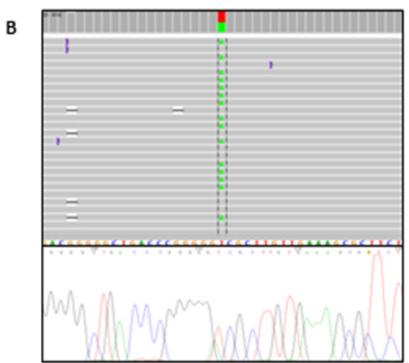

Figure 2: Mutational landscape in 6 cHL-derived cell lines and Sanger sequencing validation. (A) The diagram shows the distribution of mutations per cell line. One SNV is indicated in red, while two SNVs per gene are indicated in dark red. Black boxes correspond to SNVs validated by Sanger sequencing. (B) Representative example, CARD11 mutation in the KMH2 cell line; IGV diagram (Ion Torrent sequencing) and Sanger sequencing representation. 


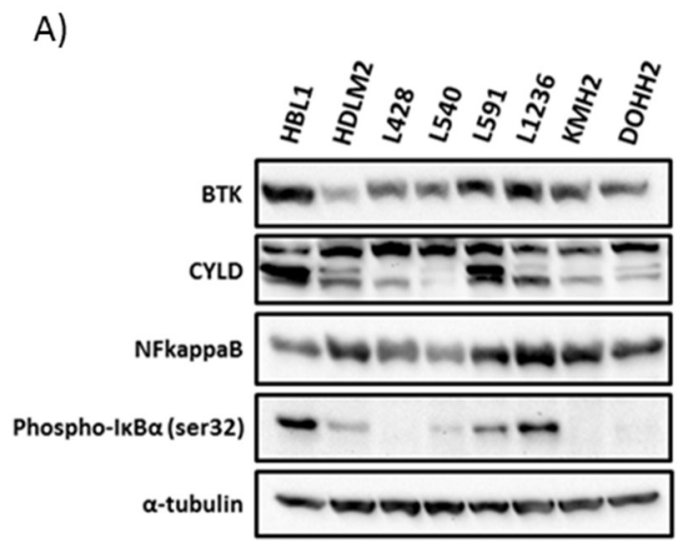

B)

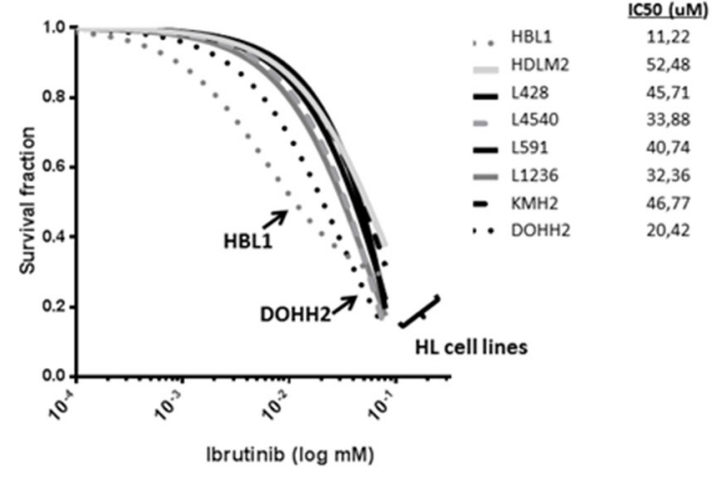

C)

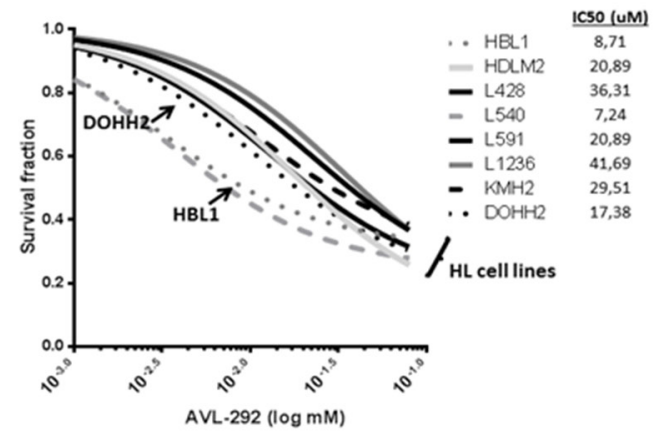

Figure 3: Functional studies in cHL-derived and DLBCL-derived cell lines. (A) Western blot analysis of total BTK, CYLD truncation, NFKB (p52 isoform), and phospho-IkBa. (B and $\mathbf{C}$ ) Activity of BTK selective inhibitors in cHL-derived and DLBCL-derived cell lines. $\mathrm{IC}_{50}$ range calculation of HBL1, HDLM2, L540, and L1236 cell lines in the presence of different concentrations of Ibrutinib or AVL-292, after 48 hours.

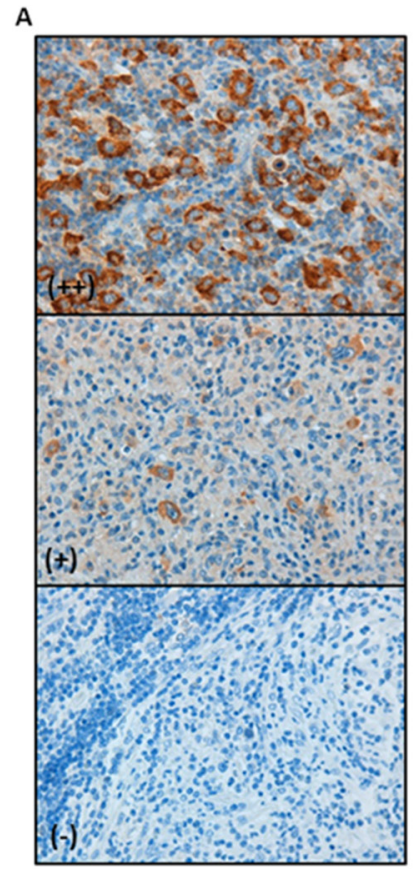

B

\begin{tabular}{|l|c|}
\hline \multicolumn{1}{|c|}{ Expression level of Btk } & $\begin{array}{c}\text { \# Patient } \\
\text { N (\%) }\end{array}$ \\
\hline Strong positive (++) & $4 / 53(8)$ \\
\hline Normal positive (+) & $34 / 53(64)$ \\
\hline Negative (-) & $9 / 53(17)$ \\
\hline Not assessable (NA) & $6 / 53(11)$ \\
\hline
\end{tabular}

C

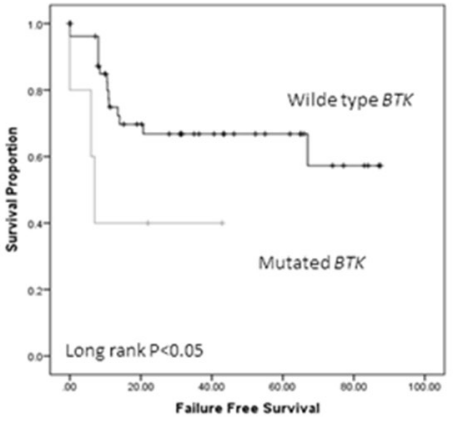

D

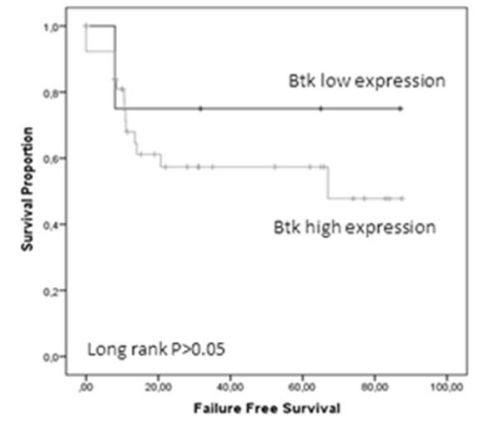

Figure 4: Btk IHC expression in HRS cells and Its correlation with survival. (A) Representative examples of IHC for Btk expression in cHL tissues. (B) Distribution of Btk protein expression in our series. Positivity (+) was concluded for cases with a level of expression comparable to that seen in normal germinal center B lymphocytes. (C) Kaplan-Meier survival curves demonstrate longer FFS in wt-BTK cases $(\mathrm{P}<0.05)$. (D) Survival curves demonstrate a longer FFS in cases with a low level of expression of Btk protein $(\mathrm{P}=$ n.s.). 
The most frequent genetic lesions potentially affect relevant signaling pathways in B cell biology (see Supplementary Materials): JAK/STAT, NF-kappaB, and numerous variants of genes affecting the $\mathrm{B}$ cell receptor (BCR) pathway, such as BTK, CARD11, and BCL10, among others. Epigenetic regulation also seems to be a common target for mutational events (EP300, CREBBP).

$E P 300$ encodes an adenovirus E1A-associated cellular p300 transcriptional coactivator protein and functions as a histone acetyltransferase and regulates transcription via chromatin remodeling. Histone acetylation gives an epigenetic tag for transcriptional activation. It mediates cAMP-gene regulation by binding specifically to phosphorylated CREB protein. It also functions as an acetyltransferase for non-histone targets. Mutations in the histone acetylation domain of EP300 are present in $14 \%$ of the samples, similar to what is seen in DLBCL and follicular lymphoma $[19,20]$. Interestingly, the inhibition of the CBP/ p300 bromodomain has been recently introduced as a promising therapy for lymphoproliferative disorders [21].

$C S F 2 R B$ (colony stimulating factor 2 receptor beta common subunit) encodes the common beta chain of the high-affinity receptor for interleukin-3, interleukin-5, and granulocyte-macrophage colony-stimulating factor. Its function is critical for the activation of the JAK/STAT and MAP kinase pathways. In this series, we found low allele frequency SNVs in 7 samples $(12.3 \%)$. One particular SNV, V212I, is recurrent in 4 of the cHL cases. This alteration is located in the fibronectin type III domain (FIB). The RGD sequence (Arginine-Glycine-Aspartic acid), which is involved in the interaction with integrin, is located in this domain, and modulates a variety of cell adhesion events associated with thrombosis, inflammation and tumor metastasis [22].

STAT6 (Signal Transducer and Activator of Transcription 6, Interleukin-4 Induced) encodes a member of the STAT family of transcription factors, plays a central role in exerting IL4-mediated biological responses, and induces the expression of BCL2L1/BCL-X(L), which is responsible for the anti-apoptotic activity of IL4. We found 7 SNVs in 7 cases (12.3\% of samples), most of which are located in the DNA binding domain, as has been found in previous studies of primary mediastinal DLBCL. Functional studies in cell lines have shown that mutations in this domain reduced DNA-binding ability [10].

$B T K$ is a non-receptor tyrosine kinase that is indispensable for B lymphocyte development, differentiation, and signaling. Binding of antigens to the BCR triggers signaling that ultimately leads to B-cell activation. This gene has been implicated in the pathogenesis of chronic lymphocytic leukemia, mantle cell lymphoma, DLBCL and other B-cell malignancies. We have seen 7 different SNVs in 6 samples $(10.3 \%$ of our series). Ibrutinib is an irreversible inhibitor of BTK, binding to cysteine 481 in the protein tyrosine kinase domain (ATP binding site). Woyach et al [23] have recently identified a cysteine-to-serine mutation at the ibrutinib binding site in treated patients that results in a protein that is only reversibly inhibited, and could be associated with therapy resistance. This specific alteration is different from all the SNVs that we found in our series, located at different functional domains, mainly affecting the PH domain, which is involved in establishing the location of the protein and its membrane anchoring. The BTK subcellular localization in tumor cells is a key process for the activation of the pathway and BTK mutations affecting this functional domain may also be related with BCR signaling activation [24].

Unexpectedly, we observed numerous variants of genes affecting the BCR pathway, such as BTK, CARD11, and $B C L 10$. These findings suggest that there may be a requirement for active BCR signaling to ensure $\mathrm{cHL}$ cell viability, even though BCR is not expressed by HRS cells. Consistent with this interpretation, we found evidence of the basal activation of the pathway in cHL cell lines, and that the incubation of a panel of in vitro cell models with specific BTK inhibitors constrains cell proliferation and causes cell death. However, from our results we must also recognize the potential overlap between BCR signaling and the canonical NF-kappaB pathway, making it difficult to establish firm conclusions. In addition, some BTK-independent effect of the inhibitors in different cell models cannot be ruled out. Previous studies reported BTK expression in only approximately $20 \%$ of patients with cHL [25], but here we detected very frequent BTK protein expression in cHL tumors, as well as some correlation between protein expression, $B T K$ gene mutation and survival. In accordance with our observations, the clinical value of ibrutinib in cHL patients was partially demonstrated in a recent communication by Hamadani et al [26], who administered ibrutinib as a single agent to two heavily pretreated patients with primary refractory cHL. One of the patients showed near-complete regression of disease two months after the initiation of therapy that lasted for 4 months. The second patient showed a stable complete response 4 months after the initiation of ibrutinib.

In conclusion, our results confirm the presence of strong genomic heterogeneity in cHL. However, it appears that recurrent targets are subject to functional mutations and suggest the existence of some tumor dependencies that could be exploited for therapeutic purposes. The activity of selective BTK inhibitors in patients with refractory cHL, as well as the inhibition of the CBP/ p300 bromodomain and JAK/STAT pathways, need to be evaluated in prospective clinical studies.

\section{MATERIALS AND METHODS}

\section{Patient samples}

Pretreatment FFPE tumor samples and clinical data from $57 \mathrm{cHL}$ patients were obtained from the files of 
participant institutions. cHL was confirmed histologically in all cases by central review.

Samples were collected in accordance with the technical and ethical procedures of the Spanish National Biobank Network, including anonymization processes and written informed consent, according to the Helsinki Declaration. Approval was obtained from the institutional review board (Clinical Research Ethical Committee, ref. 354/12).

\section{Gene selection and Ampliseq design}

Target genes were selected by analyzing the mutational profile of cHL with Illumina GAII and Sure Select technology (Agilent Technologies, Santa Clara, CA, USA) in an initial discovery cohort of 7 tumor tissue samples (freshly frozen) from $4 \mathrm{cHL}$ cases, with a targeted analysis of 522 genes involved in lymphomagenesis and $\mathrm{B}$ and $\mathrm{T}$ cell-related pathways (Supplementary Table 1). Sequences were analyzed with the RAMSES (Realignment-Assisted Minimum Evidence Spotter) algorithm [27], which has been specifically designed to detect low-frequency variants for the Illumina platform. This software uses minimum high confidence evidence, based on the use of multiple short read aligners, of the presence of sequence variants at a specific position. Considering the great extent of coverage obtained in this project, we established a minimum of 20 high-confidence reads reporting a different base in a specific mutation to conclude the presence of a mutation. We also filtered out all the variants reported in dbSNP and the 1000 Genomes project as probable germline variants. Small insertions and deletions (indels) were identified using PINDEL [28].

Two predictive algorithms (PROVEAN [29] and Alamut [13]) indicated that 54 variants of 48 genes had a deleterious effect on protein function. From these results, we selected 25 genes filtered by established criteria based on sequencing quality and discovery cohort population frequency (consistently mutated in at least two samples). As additional controls, we added 6 genes (detected in single samples) to this design with previously reported mutations in diffuse large B-cell lymphomas (DLBCLs) or in cHL, as well as 4 genes of biological relevance in this type of lymphoma (Supplementary Table 2). These 35 coding regions from target genes were included in an Ampliseq Custom Panel for sequencing using the Ion Torrent platform.

\section{Sequencing techniques}

To isolate DNA, tumor samples were enriched in HRS cells by selecting the most representative regions (those containing more than $10 \%$ of tumor cells), using a 1-mm-diameter puncher (Quick-Ray Tissue Microarray System, IHC World, Woodstock, MD, USA) from tumor issues of at least 1-mm thickness.
DNA was extracted from FFPE tissue and from cell lines using standard procedures. Ion Torrent adapterligated libraries were constructed using an Ampliseq Custom Panel (Thermo Fisher Scientific, NY, USA), including the 35 selected genes distributed in 353 amplicons, starting with $10 \mathrm{ng}$ of genome DNA and following the manufacturer's protocol.

Sample emulsion PCRs and enrichment were performed using Ion PGM Template OT2 200 Kit (Thermo Fisher Scientific), and the libraries were sequenced using 318 v2 chips with Ion PGM Sequencing 200 v2 (Thermo Fisher Scientific). To minimize false-positive rates, all sequencing procedures were done in duplicate (parallel libraries constructed from two independent PCRs from separate aliquots of isolated genomic DNA). For filtering polymorphisms and germinal variants we included the available germline DNA from 5 cases in order to generate control pool DNA.

\section{Variant calling and screening for somatic mutations}

The sequencing data were analyzed with the Torrent Suite program with the "variant caller" plug-in program, selecting somatic low stringency mode to detect SNVs with low allele frequency. We restricted the analyses to variants with a total coverage of at least $100 \mathrm{x}$, and a minimum variant coverage of $10 x$. In addition to filtering with the control pool of germline DNAs, we also filtered variants with an allele frequency $>40 \%$, to minimize the detection of germline variants. To eliminate erroneous base calling, all variants were examined with Integrative Genomics Viewer (IGV) software [30], comparing each duplicated sample and discarding non-concordant variants. In addition, to evaluate the reproducibility of this approach, we calculated the concordance ratios between duplicates (Supplementary Figure 1) [31]. Finally, functional consequences of the SNVs were predicted using the PROVEAN and Alamut algorithms, filtering variants with no damaging effect in the prediction $[13,29]$.

We also analyzed six cHL-derived cell lines (L428, L1236, HDLM2, L540, KMH2, and L591), using the same sequencing procedure and filtering criteria, and by conventional Sanger sequencing to validate high allele frequency mutations (Supplementary Table 3). Cell lines were newly obtained from the German Collection of Microorganisms and Cell Cultures (DSMZ, Braunschweigh, Germany). All cell lines were authenticated by DMSZ using DNA profiling

\section{Cell culture, drug treatment, protein extraction, and western blot analyses}

For in vitro studies we included the six cHL cell lines and DLBCL cell lines (HBL1 and DOHH2) (DSMZ). 
For functional experiments, we purchased ibrutinib (Selleckchem, Houston, TX) and AVL-292 (MedchemExpress, Monmouth Junction, NJ) selective BTK (Bruton tyrosine kinase) inhibitors. To calculate the half-maximal inhibitory concentration $\left(\mathrm{IC}_{50}\right), 20,000$ cells were incubated with various concentrations of ibrutinib or AVL-292 for 48 hours. Viable cells were quantified by the AlamarBlue protocol (Fisher Scientific, Waltham, MA), following the manufacturer's instructions. Experiments were performed in duplicate and repeated at least three times.

Apoptosis was estimated after 8 hours of treatment at $37^{\circ} \mathrm{C}$, by analyzing PARP cleavage by western blot. Additional western blot analyses were done using monoclonal antibodies against CYLD N-terminal (ab153698) (ABCAM, Cambridge, UK), Phospho-BTK (Tyr223), Phospho-IкB $\alpha$ (Ser32) (14D4) (Cell Signaling, Danvers, MA), BTK (7F12H4) (Santa Cruz Biotechnology, Santa Cruz, CA), NFkB p52 (MERCK, Madrid, Spain) and $\alpha$-tubulin (Sigma Aldrich, St. Louis, MO).

\section{Immunohistochemistry (IHC)}

Representative tumor areas from FFPE tumor samples were included in duplicate in a tissue microarray (TMA). IHC analysis was performed using heat-induced epitope retrieval and standard procedures, using antiBtk monoclonal antibody (7F12H4, Santa Cruz). Protein expression was quantified using an automated scan, Chroma Vision Systems-ACIS III (DAKO, Glostrup, Denmark), as previously described [32].

\section{Statistical analyses}

Correlations between variables and overall survival (OS) and failure-free survival (FFS) were estimated by the Kaplan-Meier method and the curves were compared using the log-rank test. Differences were considered statistically significant for values of $\mathrm{P}<0.05$. All statistical analyses were performed using SPSS version 17.0 (SPSS Inc., Chicago, IL).

\section{Author contributions}

E.M. and A.D.-L. performed the research, analyzed the data, and wrote the paper. A.M.M.-M., I.V., and B-S.-E. performed the research and analyzed the data. M.J.M., C.S., F.B., J.M., M.E., M.P. and C.M. contributed samples/patient data and interpreted the data. M.A.P, M.S.-B., and J.F.G designed the study, supervised the research, and wrote the paper. All authors contributed to the preparation of the manuscript, revised the draft, and approved the final version for submission.

\section{ACKNOWLEDGMENTS AND FUNDING}

This work was supported by grants from the Plan Nacional de I+D+I co-financed by the ISCIII-
Subdirección General de Evaluación and the Fondo Europeo de Desarrollo Regional (FEDER), PI12/1832, RTICC RD06/0020/0107, PI14/00221, CIBER de Cancer, PIE15/0081 and PI16/01294, the Spanish Association for Cancer Research (AECC), and by funds of the U.T M.D. Anderson Cancer Center. MSB currently holds a Miguel Servet contract (CP11/00018 and CPII16/00024) from the ISCIII- MINECO-AES-FEDER (P.N.I+D+I 2008-2011), Spain. The authors would like to thank Dr. Gema MorenoBueno for her kind gift of the HEK293T and HeLa cell lines.

\section{CONFLICTS OF INTEREST}

The authors declare no conflicts of interest.

\section{REFERENCES}

1. Küppers R, Engert A, Hansmann ML. Hodgkin lymphoma. J Clin Invest. 2012; 122:3439-3447.

2. Schwering I, Bräuninger A, Klein U, Jungnickel B, Tinguely M, Diehl V, Hansmann ML, Dalla-Favera R, Rajewsky K, Küppers R. Loss of the B-lineage-specific gene expression program in Hodgkin and Reed-Sternberg cells of Hodgkin lymphoma. Blood. 2003; 101:1505-1512.

3. Theil J, Laumen H, Marafioti T, Hummel M, Lenz G, Wirth $\mathrm{T}$, Stein H. Defective octamer-dependent transcription is responsible for silenced immunoglobulin transcription in Reed-Sternberg cells. Blood. 2001; 97:3191-3196.

4. Ammerpohl O, Haake A, Pellissery S, Giefing M, Richter J, Balint B, Kulis M, Le J, Bibikova M, Drexler HG, Seifert M, Shaknovic R, Korn B, et al. Array-based DNA methylation analysis in classical Hodgkin lymphoma reveals new insights into the mechanisms underlying silencing of B cell-specific genes. Leukemia. 2012; 26:185-188.

5. Emmerich F, Theurich S, Hummel M, Haeffker A, Vry MS, Döhner K, Bommert K, Stein H, Dörken B. Inactivating I kappa B epsilon mutations in Hodgkin/Reed-Sternberg cells. J Pathol. 2003; 201:413-420.

6. Schmitz R, Hansmann ML, Bohle V, Martin-Subero JI, Hartmann S, Mechtersheimer G, Klapper W, Vater I, Giefing M, Gesk S, Stanelle J, Siebert R, Küppers R. TNFAIP3 (A20) is a tumor suppressor gene in Hodgkin lymphoma and primary mediastinal B cell lymphoma. J Exp Med. 2009; 206:981-989.

7. Weniger MA, Melzner I, Menz CK, Wegener S, Bucur AJ, Dorsch K, Mattfeldt T, Barth TF, Möller P. Mutations of the tumor suppressor gene SOCS-1 in classical Hodgkin lymphoma are frequent and associated with nuclear phospho-STAT5 accumulation. Oncogene. 2006; 25:2679-2684.

8. Gunawardana J, Chan FC, Telenius A, Woolcock B, Kridel R, Tan KL, Ben-Neriah S, Mottok A, Lim RS, Boyle M, Rogic S, Rimsza LM, Guiter C, et al. Recurrent somatic mutations of PTPN1 in primary mediastinal B cell 
lymphoma and Hodgkin lymphoma. Nat Genet. 2014; 46:329-335.

9. Morin RD, Mungall K, Pleasance E, Mungall AJ, Goya R, Huff RD, Scott DW, Ding J, Roth A, Chiu R, Corbett RD, Chan FC, Mendez-Lago M, et al. Mutational and structural analysis of diffuse large B-cell lymphoma using wholegenome sequencing. Blood. 2013; 122:1256-1265.

10. Ritz O, Guiter C, Castellano F, Dorsch K, Melzner J, Jais JP, Dubois G, Gaulard P, Möller P, Leroy K. Recurrent mutations of the STAT6 DNA binding domain in primary mediastinal B-cell lymphoma. Blood. 2009; 114:1236-1242.

11. Lenz G, Davis RE, Ngo VN, Lam L, George TC, Wright GW, Dave SS, Zhao H, Xu W, Rosenwald A, Ott G, MullerHermelink HK, Gascoyne RD, et al. Oncogenic CARD11 mutations in human diffuse large B cell lymphoma. Science. 2008; 319:1676-1679.

12. Reichel J, Chadburn A, Rubinstein PG, Giulino-Roth L, Tam W, Liu Y, Gaiolla R, Eng K, Brody J, Inghirami G, Carlo-Stella C, Santoro A, Rahal D, et al. Flow sorting and exome sequencing reveal the oncogenome of primary Hodgkin and Reed-Sternberg cells. Blood. 2015; 125:1061-1072.

13. Choi Y, Sims GE, Murphy S, Miller JR, Chan AP. Predicting the functional effect of amino acid substitutions and indels. PLoS One. 2012; 7:e46688.

14. Liu Y, Abdul Razak FR, Terpstra M, Chan FC, Saber A, Nijland M, van Imhoff G, Visser L, Gascoyne R, Steidl C, Kluiver J, Diepstra A, Kok K, et al. The mutational landscape of Hodgkin lymphoma cell lines determined by whole-exome sequencing. Leukemia. 2014; 28:2248-2251.

15. Canellos GP, Niedzwiecki D. Long-term follow-up of Hodgkin's disease trial. N Engl J Med. 2002; 346:1417-1418.

16. Liu X, Yu H, Yang W, Zhou X, Lu H, Shi D. Mutations of NFKBIA in biopsy specimens from Hodgkin lymphoma. Cancer Genet Cytogenet. 2010; 197:152-157.

17. Maggio EM, Van Den Berg A, de Jong D, Diepstra A, Poppema S. Low frequency of FAS mutations in ReedSternberg cells of Hodgkin's lymphoma. Am J Pathol. 2003; 162:29-35.

18. Eberle FC, Salaverria I, Steidl C, Summers TA, Pittaluga $\mathrm{S}$, Neriah SB, Rodriguez-Canales J, Xi L, Ylaya K, Liewehr D, Dunleavy K, Wilson WH, Hewitt SM, et al. Gray zone lymphoma: chromosomal aberrations with immunophenotypic and clinical correlations. Mod Pathol. 2011; 24:1586-1597.

19. Morin RD, Mendez-Lago M, Mungall AJ, Goya R, Mungall KL, Corbett RD, Johnson NA, Severson TM, Chiu R, Field M, Jackman S, Krzywinski M, Scott DW, et al. Frequent mutation of histone-modifying genes in non-Hodgkin lymphoma. Nature. 2011; 476:298-303.
20. Pasqualucci L, Dominguez-Sola D, Chiarenza A, Fabbri G, Grunn A, Trifonov V, Kasper LH, Lerach S, Tang H, Ma J, Rossi D, Chadburn A, Murty VV, et al. Inactivating mutations of acetyltransferase genes in B-cell lymphoma. Nature. 2011; 471:189-195.

21. Picaud S, Fedorov O, Thanasopoulou A, Leonards K, Jones K, Meier J, Olzscha H, Monteiro O, Martin S, Philpott M, Tumber A, Filippakopoulos P, Yapp C, et al. Generation of a selective small molecule inhibitor of the $\mathrm{CBP} / \mathrm{p} 300$ bromodomain for leukemia therapy. Cancer Res. 2015; 75:5106-5119.

22. Riccioni R, Diverio D, Riti V, Buffolino S, Mariani G, Boe A, Cedrone M, Ottone T, Foà R, Testa U. Interleukin (IL)-3/granulocyte macrophage-colony stimulating factor/ IL-5 receptor alpha and beta chains are preferentially expressed in acute myeloid leukaemias with mutated FMSrelated tyrosine kinase 3 receptor. Br J Haematol. 2009; 144:376-387.

23. Woyach JA, Furman RR, Liu TM, Ozer HG, Zapatka M, Ruppert AS, Xue L, Li DH, Steggerda SM, Versele M, Dave SS, Zhang J, Yilmaz AS, et al. Resistance mechanisms for the Bruton's tyrosine kinase inhibitor ibrutinib. N Engl J Med. 2014; 370:2286-2294.

24. Mohamed AJ, Yu L, Bäckesjö CM, Vargas L, Faryal R, Aints A, Christensson B, Berglöf A, Vihinen M, Nore $\mathrm{BF}$, Smith CI. Bruton's tyrosine kinase (Btk): function, regulation, and transformation with special emphasis on the PH domain. Immunol Rev. 2009; 228:58-73.

25. Fernández-Vega I, Quirós LM, Santos-Juanes J, Pane-Foix M, Marafioti T. Bruton's tyrosine kinase (Btk) is a useful marker for Hodgkin and B cell non-Hodgkin lymphoma. Virchows Arch. 2015; 466:229-235.

26. Hamadani M, Balasubramanian S, Hari PN. Ibrutinib in refractory classic Hodgkin's lymphoma. N Engl J Med. 2015; 373:1381-1382.

27. Martínez N, Almaraz C, Vaqué JP, Varela I, Derdak S, Beltran S, Mollejo M, Campos-Martin Y, Agueda L, Rinaldi A, Kwee I, Gut M, Blanc J, et al. Whole-exome sequencing in splenic marginal zone lymphoma reveals mutations in genes involved in marginal zone differentiation. Leukemia. 2014; 28:1334-1340.

28. Ye K, Schulz MH, Long Q, Apweiler R, Ning Z. Pindel: a pattern growth approach to detect break points of large deletions and medium sized insertions from paired-end short reads. Bioinformatics. 2009; 25:2865-2871.

29. Duzkale H, Shen J, McLaughlin H, Alfares A, Kelly MA, Pugh TJ, Funke BH, Rehm HL, Lebo MS. A systematic approach to assessing the clinical significance of genetic variants. Clin Genet. 2013; 84:453-463.

30. Thorvaldsdóttir H, Robinson JT, Mesirov JP. Integrative Genomics Viewer (IGV): high-performance genomics data visualization and exploration. Brief Bioinform. 2013; 14:178-192. 
31. Qi Y, Liu X, Liu CG, Wang B, Hess KR, Symmans WF, Shi W, Pusztai L. Reproducibility of variant calls in replicate next generation sequencing experiments. PLoS One. 2015; 10:e0119230.

32. Sánchez-Espiridión B, Martin-Moreno AM, Montalbán C, Medeiros LJ, Vega F, Younes A, Piris MA, Garcia
JF. Immunohistochemical markers for tumor associated macrophages and survival in advanced classical Hodgkin's lymphoma. Haematologica. 2012; 97:1080-1084. 